\section{(6) OPEN ACCESS}

\title{
The invasive assessment of coronary atherosclerosis and stents using optical coherence tomography: a clinical update
}

\author{
Muhammad Asrar ul Haq, ${ }^{1,2}$ Jamie Layland, ${ }^{3}$ Vivek Mutha, ${ }^{1,2}$ Peter Barlis ${ }^{1,2,3}$
}

1Department of Medicine, University of Melbourne, Melbourne, Australia

${ }^{2}$ Department of Cardiology, The Northern Hospital,

Melbourne, Australia

${ }^{3}$ Department of Cardiology, St Vincent's Hospital, Melbourne, Australia

\section{Correspondence to} Dr Muhammad Asrar ul Haq Department of Cardiology, The Northern Hospital, 185 Cooper Street, Epping, Melbourne 3076, Australia; hissper@gmail.com

Received 1 May 2013 Revised 21 June 2013 Accepted 30 June 2013
To cite: Asrar ul Haq M Layland J, Mutha V, et al. Heart Asia Published Online First: [please include Day Month Year] doi:10.1136/ heartasia-2013-010328

\begin{abstract}
Ischaemic heart disease (IHD) remains one of the leading causes of death. Atherosclerosis has been intensely researched given the IHD prevalence and the financial impacts on healthcare systems. More recently, in vivo characterisation of coronary atherosclerotic plaque and tissue responses following stent implantation in a coronary artery has been made possible by a novel technology called optical coherence tomography (OCT). OCT is a light-based, invasive, intracoronary imaging modality long applied to the field of ophthalmology and now in clinical use worldwide. It gives a unique view of within the coronary artery using near-infrared light with a resolution of 15 microns, 10 times higher than other invasive coronary imaging techniques like intravascular ultrasound. The technology is being adopted to comprehensively detect features that make plaques 'vulnerable' (eg, large lipid pool, thin, fibrous-cap atheroma), whether stents are implanted optimally within the artery, and visualise the small layers of tissue that form over stent metal surfaces over time, which in turn may provide surrogate markers for long-term stent safety and help guide the optimal duration of dual antiplatelet therapy, a topic of big discussion at the current point of time.
\end{abstract}

\section{INTRODUCTION}

Ischaemic heart disease (IHD) remains one of the leading causes of death despite vast improvements in medical knowledge and care. It is well known that the major pathophysiology of IHD is the development of atherosclerosis. There has been increasing sophisticated means of visualising these coronary vessels for diagnostic and treatment purposes. These methods include non-invasive means, such as multidetector-row CT or MRI, and invasive methods, such as angiography, intravascular ultrasound (IVUS) and fractional flow reserve (FFR). More recently, optical coherence tomography (OCT) has been applied to visualise and characterise atherosclerotic plaques with exciting potential in the management of IHD. This technique was introduced in Australia in 2009.

With the increasing uptake in intervention cardiology, recent consensus guidelines and recommendations on the role and use of OCT have been proposed focusing on development of uniform terminology, standards on use of the technology, interpretation of the images and reporting of results. Here, we present a brief review of this newly introduced modality to examine the diagnosis and impact of invasive treatment on the atherosclerotic disease in coronary arteries as compared with the other invasive imaging methods.

\section{ATHEROSCLEROSIS}

Atherosclerotic plaque in the coronary tree may manifest as either an acute coronary syndrome (ACS) or stable angina pectoris. An ACS is long thought to be triggered by the rupture of vulnerable atherosclerotic plaque. ${ }^{12}$ The hallmark of the so-called 'vulnerable plaque' is a thin-cap fibroatheroma (TCFA) with macrophage infiltration surrounding a lipid-rich necrotic core. ${ }^{3-6}$ This is in contrast to patients with stable angina pectoris who may have coronary flow-limiting vulnerable plaque without acute plaque rupture. ${ }^{7}$ Autopsy studies suggest that it is the rupture of these vulnerable plaques with TCFA that cause coronary events. Hence, identification and more aggressive management of these patients may prevent future coronary events. Imaging of the coronary arteries has facilitated localisation and treatment of acute thrombi and atherosclerotic plaques thereby providing greater insight into the pathophysiology of coronary artery disease.

\section{OPTICAL COHERENCE TOMOGRAPHY}

The in vivo visualisation of vulnerable plaque is now enhanced with high-resolution imaging. With its high resolution and ability to detect the lumen diameter in relation to vulnerable plaques and stents characteristics such as struts apposition and tissue coverage, the OCT can provide additional information not possible with other invasive coronary imaging techniques including coronary angiography, IVUS and FFR.

For more than 40 years, coronary angiography has represented the universal, standard modality for visualisation of the coronary arteries. This luminogram technique provides an overview of the coronary tree, and can confirm the presence of atherosclerosis causing any flow disruption in the artery with high specificity. The prognostic relevance for subsequent cardiac events, such as acute myocardial infarction (AMI), however, is limited. The percentage diameter stenosis, in particular for a mild or moderate lesion, does not provide reliable information concerning the future risk of AMI and death. This might be explained by the inability to distinguish between stable and unstable vulnerable plaques or lack of assessment on parameters like endothelial function or coronary flow patterns.

IVUS is a percutaneous imaging technique that uses the transmission and reflection of high frequency longitudinal mechanical waves in the tissues 
to generate an image. At the tip of the IVUS catheter, which is placed over a standard angioplasty wire, a transducer emits and receives an ultrasound signal. In the normal artery, the IVUS image largely reflects the two acoustic impedances of the vessel wall, namely the border between blood and the leading edge of the intima, and at the external elastic membrane located at the media adventitia border ${ }^{8}$ (figure 1).

IVUS is a valuable, well-validated tool enabling the accurate assessment of disease burden in the intermediate atherosclerotic lesions, ambiguous left main lesions and for assessing poststenting outcomes. ${ }^{9}$ However, accurate assessment of specific plaque characteristics and subtypes is limited by the axial resolution of IVUS ( 100 microns).

Virtual Histology IVUS is a new modality that uses a technique called spectral analysis to process the raw backscattered ultrasound signal and colour code plaque into four categories (figure 2): fibrous (green), calcific (white), necrotic core (red) and fibrofatty (green/yellow). This has been validated in human and animal models with good accuracy. ${ }^{10}$ Like conventional IVUS, it lacks the resolution to be able to identify thin cap fibroatheroma, however a new entity 'IVUS derived TCFA' has recently been defined and suggested to correlate with ACSs compared with stable angina. ${ }^{11}$

FFR is another of the recent advances in technology and predicts the haemodynamic and functional significance of disease as assessed by angiography, particularly useful for the intermediate lesions defined as a luminal narrowing of $>40 \%$ but $<70 \%$. It is defined as the ratio of maximal blood flow in the stenotic territory to normal flow if, theoretically, there was no stenosis present. $^{12}$ It is a well-validated technique that was first conceived by Pijls et $a l^{13}$ in a landmark animal study in 1993 .

Use of FFR involves a pressure wire that is placed distal to a stenosis in a coronary artery of interest. The aortic pressure (Pa) represents the pressure in a coronary artery in the absence of a stenosis (figure 3), since in a normal artery without any stenosis aortic pressure is transmitted fully to the distal coronary artery. The distal pressure $(\mathrm{Pd})$ represents the pressure distal to a

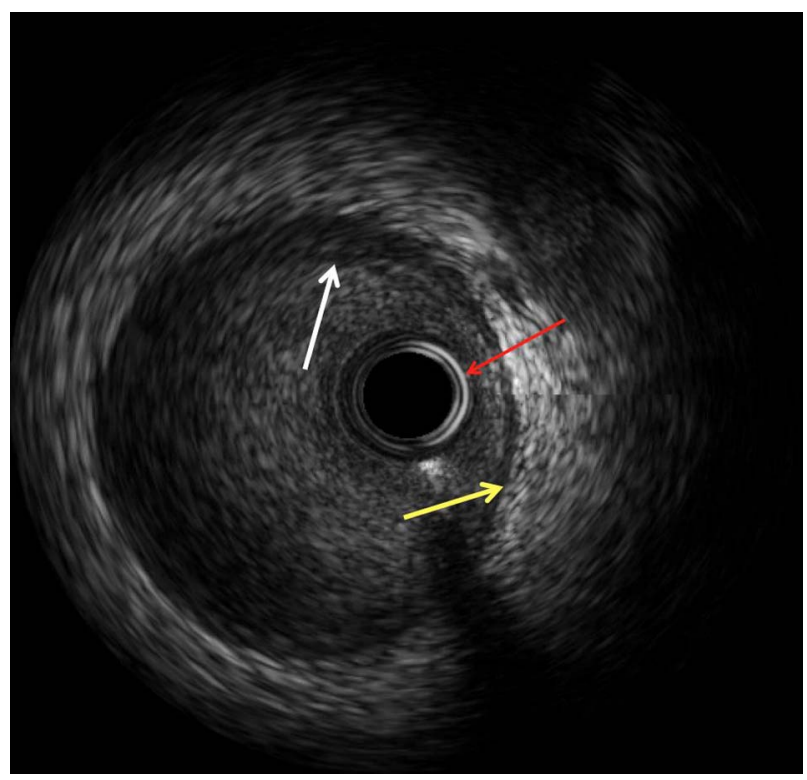

Figure 1 Normal intravascular ultrasound (IVUS) appearance: three layers identified with IVUS: Intima as highlighted by the white arrow; external elastic membrane that represents interface between media and adventitia is highlighted by the yellow arrow. Red arrow points to the IVUS catheter.

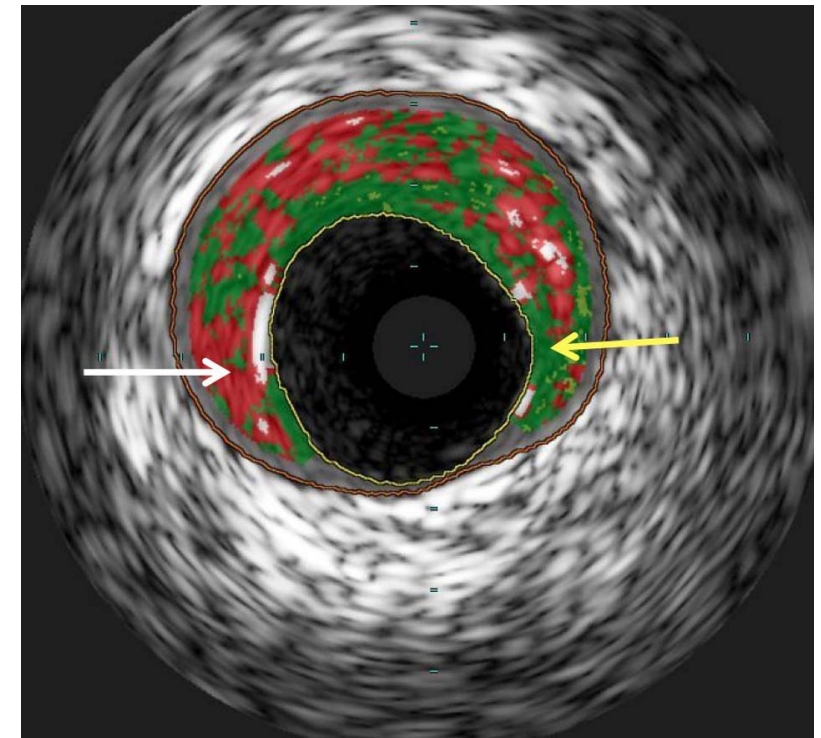

Figure 2 Virtual histology intravascular ultrasound (IVUS) appearance: A still image of a virtual histology IVUS frame from the left anterior descending artery. The white arrow is pointing to an area of necrotic core (red) with the yellow arrow pointing to an area of fibrous plaque (green). The inner yellow line points to the intimal border and the outer orange line is the external elastic membrane.

stenosis. The ratio of $\mathrm{Pd} / \mathrm{Pa}$ at hyperaemia (maximal dilation) gives the FFR. A value of $\leq 0.8$ has been validated as an acceptable ischaemic threshold. ${ }^{14}$

Using a FFR-guided strategy in the assessment of intermediate lesions in patients with single and multivessel disease has been shown to improve patient outcomes and be more cost effective than an angiographically guided strategy. ${ }^{14} 15$ There is emerging clinical evidence particularly after FAME I (FFR versus Angiography for Multivessel Evaluation) and FAME II (FFR Guided Percutaneous Coronary Intervention Plus Optimal Medical Treatment (OMT) Verses OMT) trials that use of this functional method may help in selecting appropriate patients and lesions for treatment, avoiding unnecessary procedures, reducing medical costs, and improving each patient's clinical outcomes. FFR is also useful to assess the effects of coronary stenting with a value of 0.95 associated with a significantly lower 6 month major adverse cardiac event rate compared with a value $\leq 0.8 .{ }^{16}$ However it lacks the future prediction of mortality or adverse cardiovascular events due to a haemodynamically non-significant plaque given the inability to qualitatively characterise plaque disease.

OCT on the other hand has clear advantage of the in vivo visualisation of vulnerable plaque over the above mentioned technologies. Furthermore, it can also assess tissue coverage following stent implantation and as such may provide additional insights into stent endothelialisation and late thrombosis. ${ }^{17} 18$

Compared with traditional IVUS, it has a 10 -fold higher resolution thereby giving crisp images of within the artery. ${ }^{12}$ This advantage has seen OCT successfully applied to the assessment of atherosclerotic plaque, stent apposition and tissue coverage. $^{3} 19^{20}$ It is an optical analogue of ultrasound using light rather than sound to produce an image 2122 giving it a 10 times higher resolution of 15 microns. Intracoronary imaging has never been as detailed.

OCT is an invasive imaging method performed in conjunction with coronary angiography. The patient is prepared in the standard sterile fashion with a sheath introduced into the femoral or 


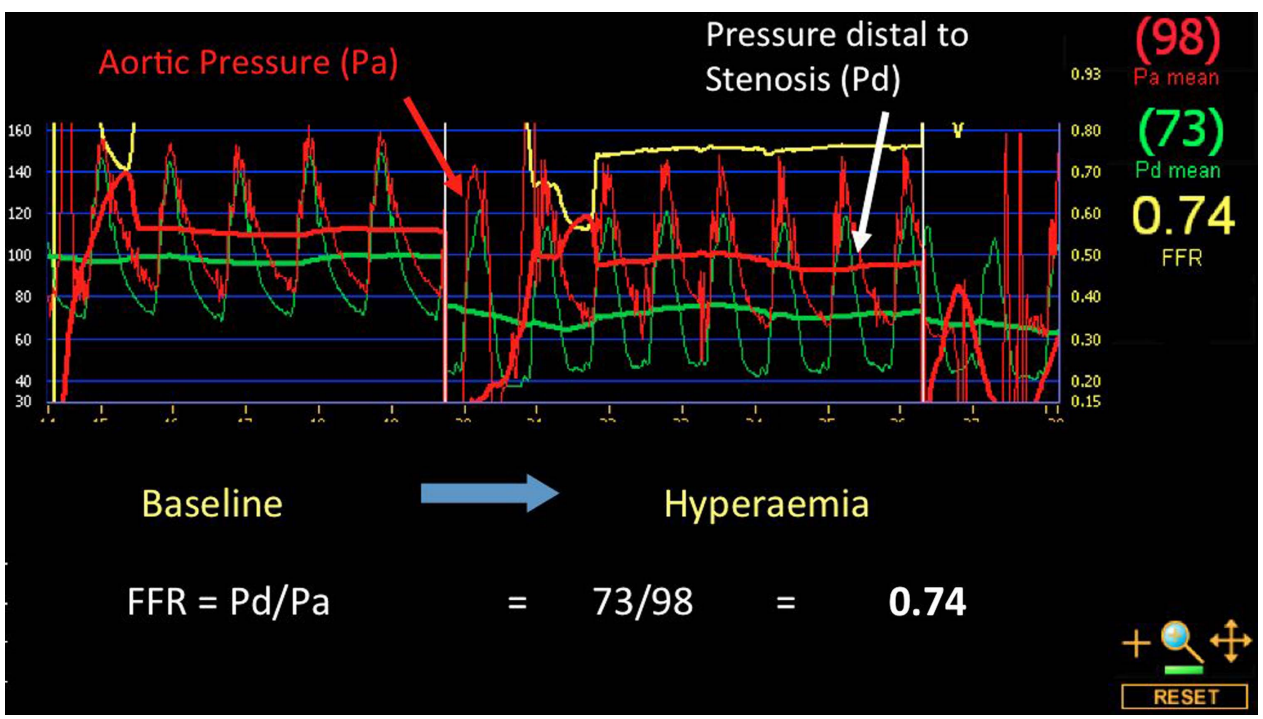

Figure 3 Fractional flow reserve (FFR) - Baseline pressure distal ( $\mathrm{Pd}$ ) and aortic ( $\mathrm{Pa}$ ) to the lesion of interest is shown to be equivalent. Following a systemic infusion of adenosine to achieve maximal hyperaemia, a significant drop in the pressure ratio is demonstrated (FFR=0.74) indicating a haemodynamically significant stenosis that warrants intervention.

radial artery. The dedicated imaging wire Dragonfly is a 0.019 inch catheter advanced within the coronary artery over a conventional guidewire. Imaging is commenced with a pullback speed of between $3.0 \mathrm{~mm} / \mathrm{s}$ and $20 \mathrm{~mm} / \mathrm{s}$ depending on the type of system being used. As light is unable to penetrate through blood, the vessel must be temporarily cleared during imaging. This is undertaken by flushing the coronary artery with contrast, as is done during coronary angiography.

OCT adds approximately $10-15$ min to the angiography procedure. It is usually well tolerated by patients. Possible symptoms during OCT imaging are similar to those in patients undergoing percutaneous coronary intervention (PCI) and are inherent with instrumentation of the coronary artery. Such symptoms include short-lived chest pain that resolves following cessation of imaging. Patient tolerance has significantly improved with advances in OCT systems with faster pullback speeds permitting more rapid evaluation of the coronary artery, significantly less contrast use, and, with minimal to no patient inconvenience. ${ }^{23}$

Although no absolute contraindications exist for imaging with OCT, care should be taken in patients with renal and left ventricular dysfunction given the requirement of additional contrast media usage during image acquisition. The amount of additional contrast is usually between $10-30 \mathrm{~mL}$ depending on the size of vessel to be imaged and speed of OCT pullback. Other rare complications including dissection, thrombotic occlusion and vasospasm, are similar to coronary angiography, inherent to invasive nature of the procedure.

\section{Clinical applications of OCT}

At present, OCT is being used as an adjunct to angiography for the detailed evaluation of coronary atherosclerosis and coronary artery stents. These devices are now the mainstay of invasive therapy for patients with established coronary artery disease and are also being adapted to patients and lesions that previously would have been treated using coronary artery bypass graft surgery.

\section{Atherosclerotic plaque assessment}

The application of OCT to plaque characterisation has been analysed in an in vitro study of more than 300 human atherosclerotic artery segments (aorta, carotid and coronary arteries). Plaque types were defined by OCT as fibrous (homogeneous, signal-rich regions), fibrocalcific (well-delineated, signal-poor regions with sharp margins) and lipid-rich (signal-poor regions and diffuse margins). Compared with histological examination, OCT had a sensitivity and specificity of $71-79 \%$ and $97-98 \%$ for fibrous plaques, 95-96\% and 97\% for fibrocalcific plaques, and 90$94.5 \%$ and $90-92 \%$ for lipid-rich plaques, respectively. ${ }^{24}$ Furthermore, in vitro data suggest that OCT is able to overcome two classical shortcomings of IVUS imaging, namely the differentiation of lipid-rich and calcified lesions. While IVUS can classify fibrotic plaques with high sensitivity (89\%) and specificity $(97 \%),{ }^{25}$ the detection of lipid-rich lesions is more difficult, with a reported sensitivity as low as $50 \%{ }^{26}$ as compared with OCT with a higher sensitivity (90-94\%) and specificity (90-02\%). ${ }^{24}$ OCT can also penetrate through calcified plaques allowing for tissue analysis behind the calcification. Furthermore, analysis of structures in front of calcium is not impeded by reverberations. ${ }^{27} 28$

At current point of time the clinical assessment of plaque by OCT remains largely qualitative with the notable exception of the measurement of thickness of the fibrous cap covering necrotic areas. Differentiation of lipid-rich, fibrous or calcified plaque is restricted to subjective, visual assessment, and is as such dependent on the observer experience and interpretation. The other limitation of OCT for plaque quantification is the inability to provide a full thickness analysis of large plaques because of its limited penetration. Despite these limitations, the clear images have attracted considerable attention and show promise in the detailed interrogation of the superficial plaque structures such as the thin, fibrous cap and necrotic core. This is well demonstrated in figure 4 where panel B shows the presence of a mixed plaque with a fibrotic component, which has a homogenous bright appearance, and lipid-rich areas which appear as signal poor regions with diffuse borders. Panel A demonstrates the presence of a small protruding tissue mass consistent with thrombus measuring $140 \times 150$ microns. Figure 5 demonstrates the same lesion following stent implantation.

\section{Thin fibrous cap}

The in vivo visualisation of a thin fibrous cap is neither possible by angiography nor by IVUS given its limited resolution (axial 

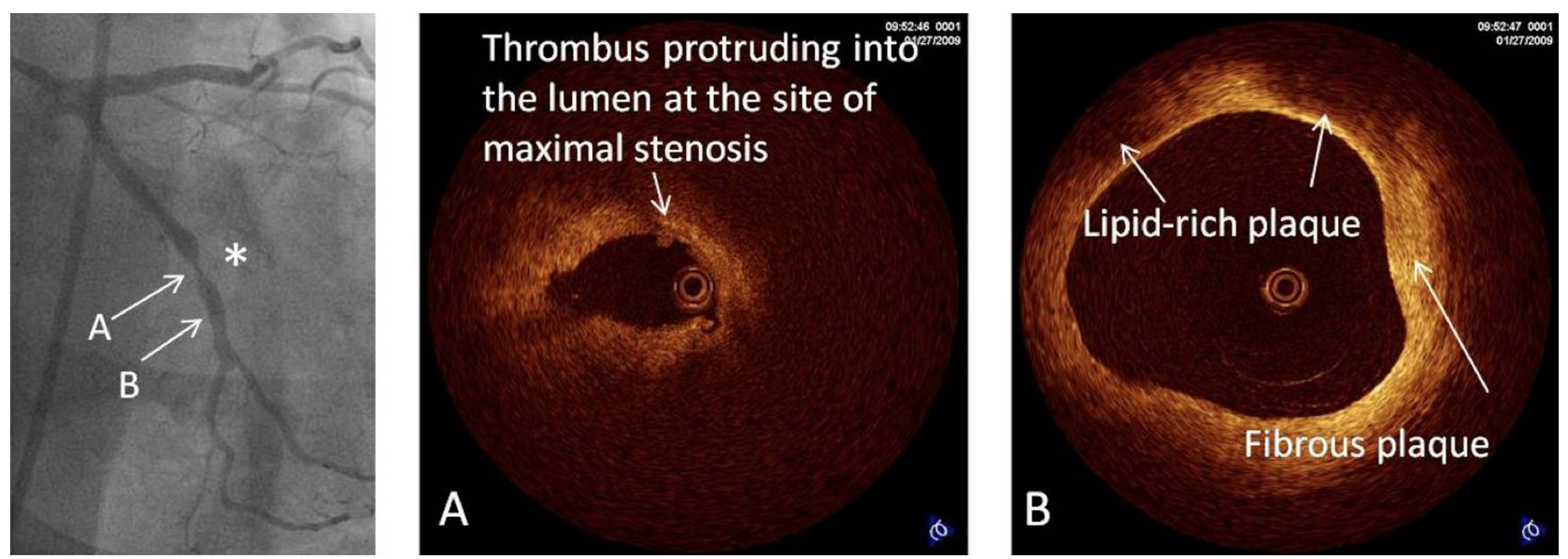

Figure 4 Coronary angiography in the right caudal view demonstrating a severe concentric stenosis in the left circumflex artery $\left({ }^{*}\right)$. Optical coherence tomography of the lesion demonstrates severe luminal narrowing with small tissue mass protruding into the lumen consistent with thrombus (A). Distal to the lesion, the left circumflex artery is seen to contain two distinct plaque types: (A) fibrous plaque is seen with a homogeneous and bright appearance (B) lipid-rich plaque with poorly reflective regions and diffuse margins with a thin bright fibrous cap consistent with thin-cap fibroatheroma.

resolution $150-200 \mathrm{~mm}$, radial resolution $200-400 \mathrm{~mm}$ ). As mentioned earlier, OCT gives a 10 times higher resolution and thus the possibility to detect thin fibrous caps. Kubo et $a l^{29}$ confirmed this in the clinical setting by applying intracoronary OCT together with IVUS and angiography to assess plaque characteristics in 30 patients presenting with AMI. Following initial mechanical thrombectomy, the incidence of plaque rupture detected by OCT was significantly higher (73\%) when compared with angiography $(47 \%, \mathrm{p}=0.035)$ and IVUS $(40 \%$, $\mathrm{p}=0.009)$. The incidence of TCFA was $83 \%$ in this patient population and only OCT was able to estimate the fibrous cap thickness (mean $49 \pm 21 \mu \mathrm{m}$ ). Interestingly, intracoronary thrombus was observed in all cases by OCT and angiography but was identified only in $33 \%$ of patients by IVUS $(p<0.001)$. The potential for OCT in such circumstances is clearly evident with intense research currently ongoing to detect vulnerable lesions early in their natural history with a potential to affect morbidity and mortality.

\section{Stent tissue coverage}

Stent thrombosis is a well known and potentially catastrophic complication following stent implantation, particularly with the advent of drug-eluting stents (DES). Mortality rate is approximately $45 \% .^{30} 31$ Patient risk factors associated with stent thrombosis include diabetes mellitus, smoking, obesity, low ejection fraction and renal insufficiency. ${ }^{32-35}$ Postmortem studies have also suggested persistent fibrin deposition and more importantly, lack of endothelial coverage of stents, malapposition or incomplete apposition, and struts penetrating necrotic core as risk factors in particular related to late stent thrombosis. ${ }^{36}$ Several OCT studies have reported a neointima hyperplasia at 612 months follow-up after DES implantation with a median thickness that falls below the sensitivity of IVUS $(100 \mu \mathrm{m})$ in a large proportion of lesions. ${ }^{37-39}$ OCT studies have shown that DES struts may present lack of tissue coverage even at 2 years after stent implantation ${ }^{40}$ and that the rate of covered struts differs across patients with different clinical syndromes. ${ }^{41}$ Although the lack of detection of a thin layer of tissue of $10 \mu \mathrm{m}$ does not rule out the presence of strut coverage by endothelial cells, OCT still has a far superior resolution to IVUS. This has led to several studies addressing the process of strut healing in different types of DES. In a subgroup of the multicentre, randomised LEADERS trial, OCT was used to assess the difference in uncovered struts between biolimus-eluting stent (BES) with biodegradable polymer, and sirolimus-eluting stent (SES) at 9 month follow-up. ${ }^{42}$ Twenty patients in the BES group (29 lesions with
Figure 5 Demonstrating the angiographic result following implantation of a $3.5 \times 12 \mathrm{~mm}$ stent to the lesion in the left circumflex artery. Optical coherence tomography pullback of the stented segment showed that stent struts (arrows) were well apposed to the vessel wall.

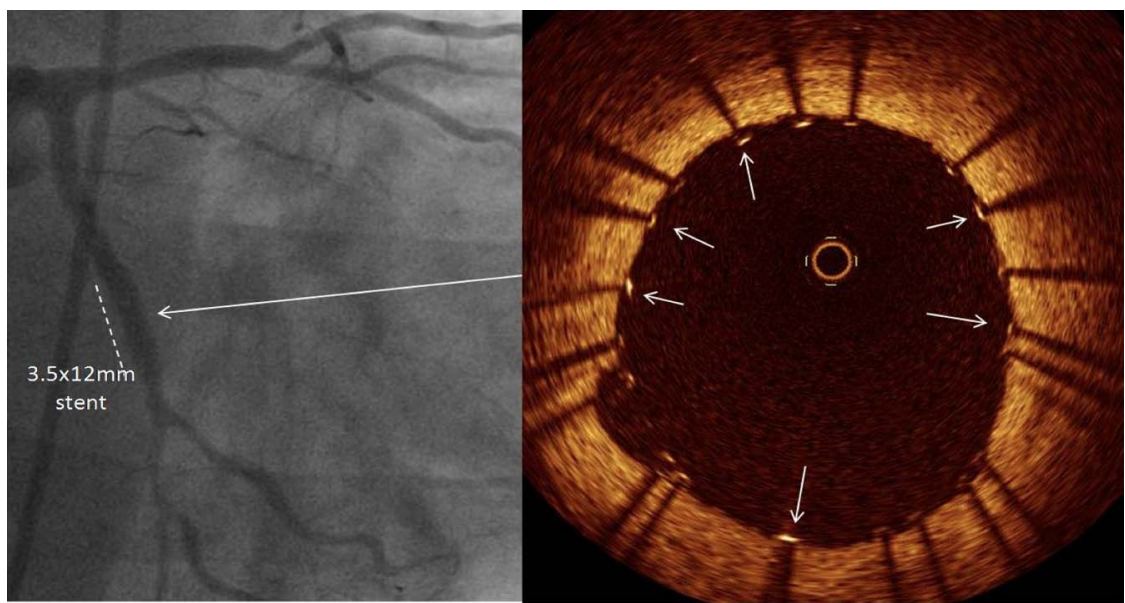



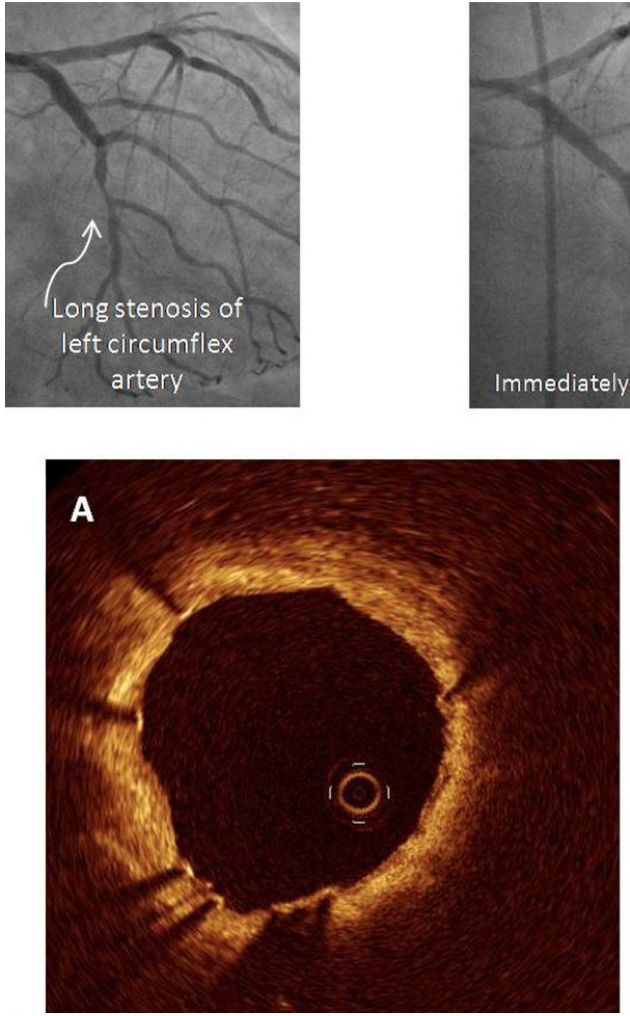
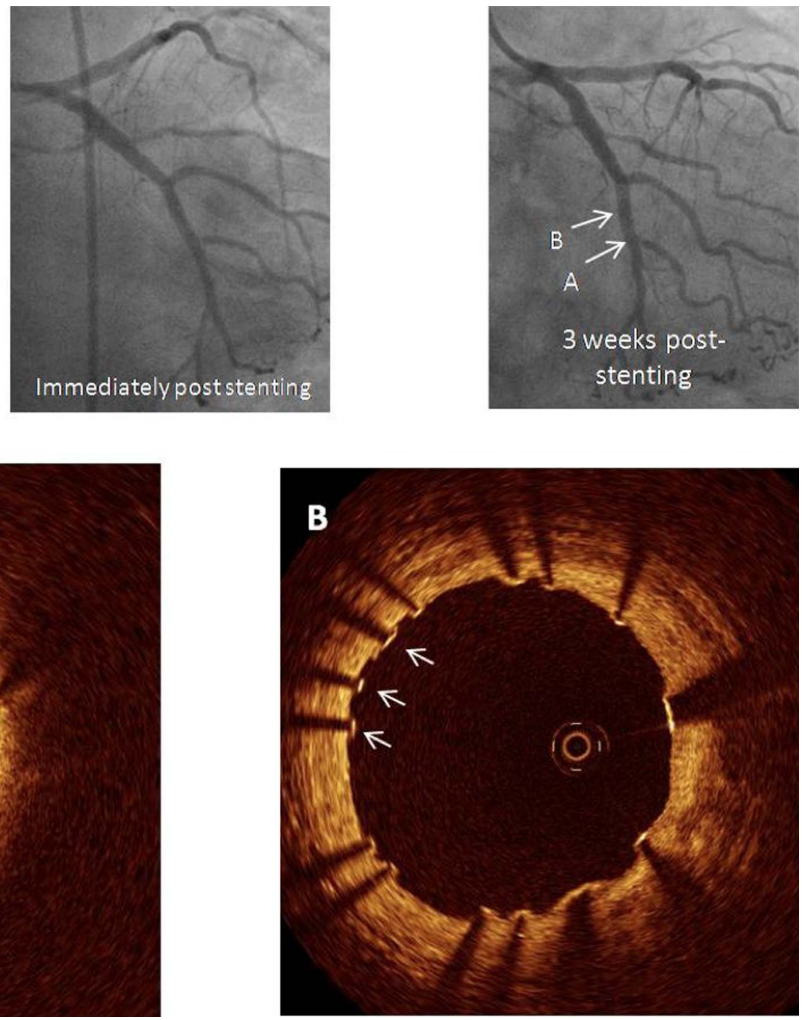

Figure 6 In this example, optical coherence tomography was performed to examine tissue coverage of a stent implanted 3 weeks prior to the left circumflex artery. At this early stage, many struts are seen with a very thin layer of tissue coverage while others still remain bare (B, arrows).

4592 struts) and 26 patients in the SES group (35 lesions with 6476 struts) underwent OCT. A total of 83 struts were uncovered in the BES group and 407 struts were uncovered in the SES group (weighted difference $-1.4 \%$, 95\% CI 23.7 to 0.0 , $\mathrm{p}=0.04)$. Three lesions in the BES group and 15 lesions in the SES group that had $\geq 5 \%$ of all struts uncovered (difference

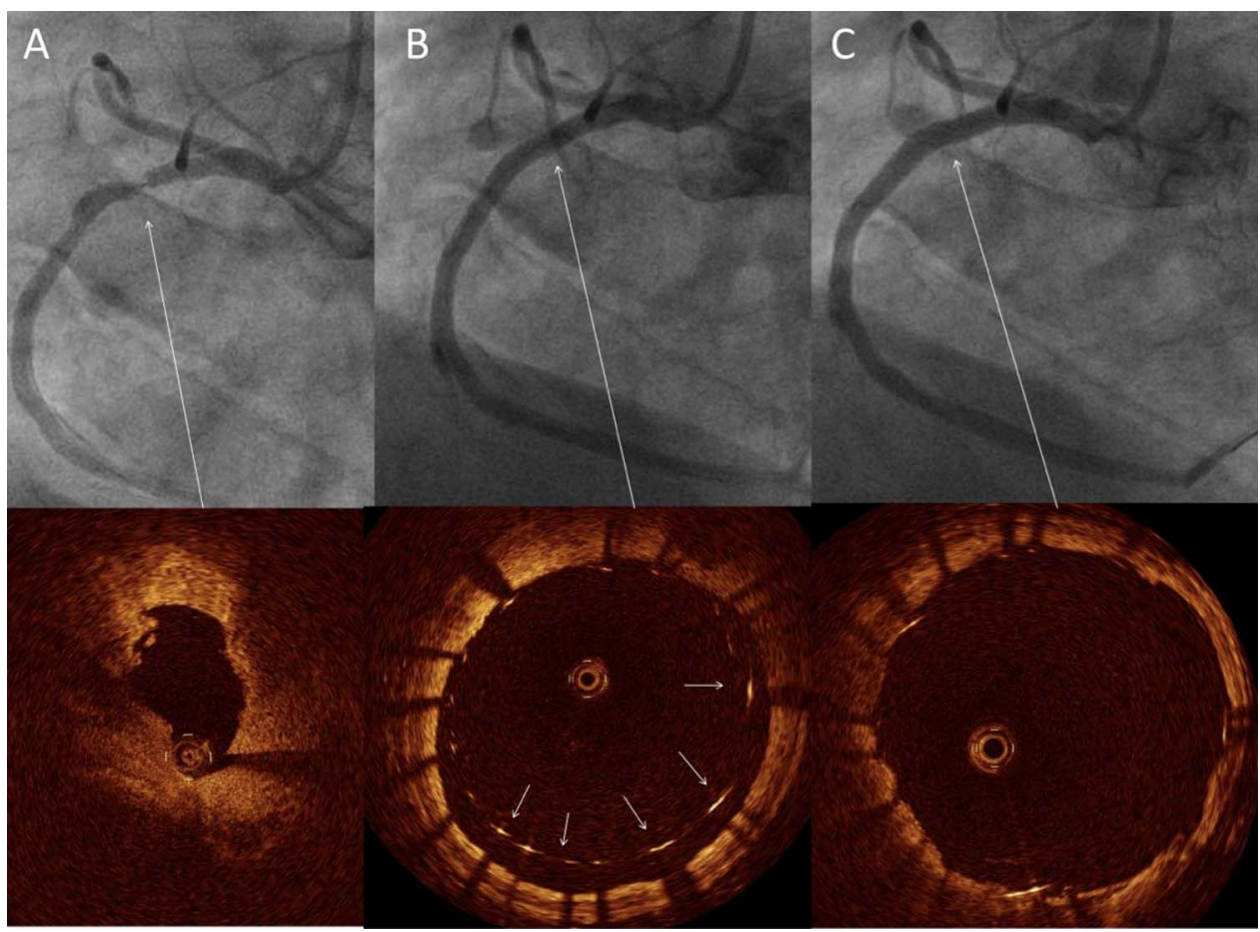

Figure 7 Angiographic and corresponding optical coherence tomography (OCT) images. (A) Left anterior oblique view of the right coronary artery with severe stenosis in the mid segment. OCT here showed a severe reduction in lumen area with thrombus in the lumen. Immediately following stent implantation, angiography confirmed good stent expansion however, OCT showed struts to be grossly malapposed (B, arrows). Post dilatation to high pressure, OCT confirmed excellent stent apposition (C). 
$-33.1 \%, 95 \% \mathrm{CI}-61.7$ to $-10.3, \mathrm{p}<0.01)$, suggestive of strut coverage at an average follow-up of 9 months to be more complete in patients allocated to BESs as compared with SESs.

Figure 6 demonstrates OCT views of a stent in a 67 -year-old woman who had a DES implanted 3 weeks prior to the left circumflex artery. Even at this early stage, OCT clearly demonstrated that many struts had already developed tissue coverage while other struts were still bare (figure 6B, arrows). It is this ability of OCT to detect tissue coverage following stent implantation that has seen it incorporated into large, multicentre device trials of novel DES and can provide complimentary information over and above clinical and angiographic endpoints. ${ }^{38}$ This may also be important at determining the appropriate time to stop dual antiplatelet therapy currently being investigated actively.

This technology may prove useful in complementing clinical and angiographic endpoints in clinical trials looking at new and emerging stents and may provide intermediate markers of stent safety given the detailed assessment of tissue strut coverage.

\section{Stent apposition}

Contemporary stents have thicknesses of around $80-90 \mu \mathrm{m}$. OCT with its resolution of $15 \mu \mathrm{m}$ is thus able to assess stent
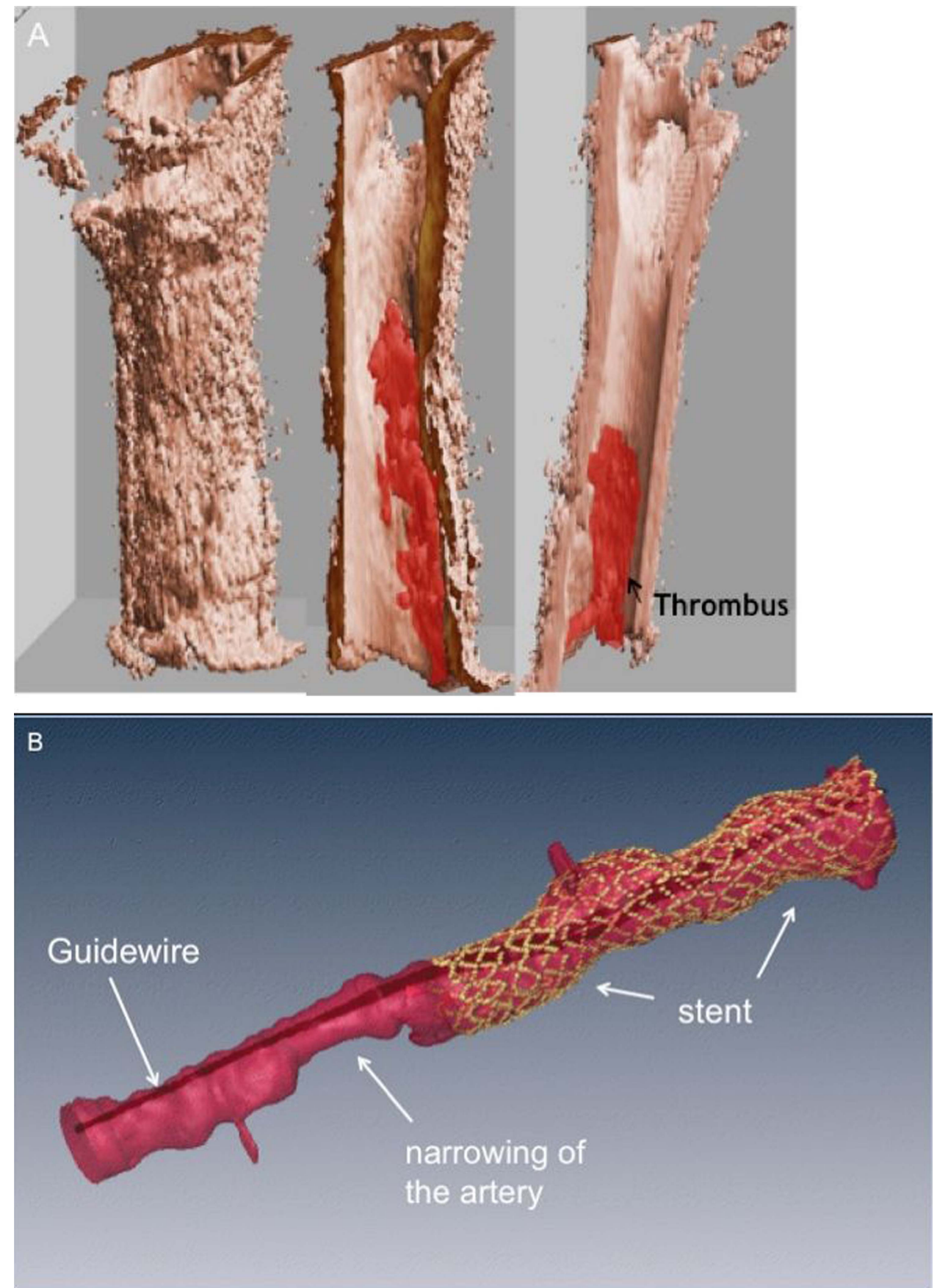

Figure 8 Three dimensional reconstruction of optical coherence tomography images. (A) Demonstrates the presence of thrombus within the lumen of the artery. (B) Shows the vessel appearance following stenting. The guidewire is seen in the centre of the artery. The stent is depicted in yellow. An area of stenosis is seen adjacent to the stented segment (Images Courtesy of Dr Joe Schmitt, LightLab Imaging, Westford, Massachusetts, USA). 
apposition better than IVUS, which has a resolution of $150 \mu \mathrm{m}$. This is well demonstrated in figure 7 in a 73 year-old patient with severe right coronary artery stenosis. Figure $7 \mathrm{~B}$ shows gross stent malapposition following deployment, despite good angiographic results. Figure $7 \mathrm{C}$ shows complete stent expansion with OCT after repeat balloon expansion.

Stent strut malapposition, one of the important predictors of stent thrombosis, can be recognised by OCTwith high sensitivity and a low intraobserver and interobserver variability as compared with IVUS and angiography. ${ }^{19}$ Furthermore, complications post PCI such as depth of dissection after balloon inflations or stent fracture $^{4344}$ can readily be assessed using OCT.

\section{OCT in the assessment and development of bioabsorbable vascular scaffolds}

OCT has been used to assess in vivo the bioabsorption process of struts of bioresorbable vascular scaffolds (BVSs), such as the everolimus-eluting BVS (Abbott Vascular, Santa Clara, California, USA) that was tested in the ABSORB study ( $\mathrm{N}=30$ patients). ${ }^{45} 46$ OCT can distinguish the rectangular polymer BVS struts that are optically transparent from the highly scattering vascular wall. Changes in the strut optical appearance at follow-up were categorised as: 'preserved box' when an intact strut footprint was present, 'open box' that marks the first OCT change in the strut footprint, dissolved 'bright box', and dissolved 'black box' that designate struts with a degraded footprint that merges into the artery wall. ${ }^{46}$ At 2 years, OCT analysis showed that $34.5 \%$ of the struts were no longer identifiable. It has been suggested that future OCT technology could be configured to allow a better distinction of polymer from proteoglycan, which may help in the development of new bioabsorbable devices.

\section{Future directions}

Rapid developments and refinements in OCT technology will permit faster pullback speeds within the artery meaning that the interrogation of the vessel will only take a short period of time $(<5 \mathrm{~s})$ and avoid excess use of contrast agents. Software upgrades will soon provide the cardiologist with a rapid assessment of the location of stent malapposition and this may be used to direct treatment with balloon post dilatation to ensure adequate stent expansion. Finally, three-dimensional reconstructions of images will give virtual 'fly-through' images of within the coronary artery, able to precisely detect lipid rich plaque, microthrombi and the position of coronary stents in relation to the vessel wall (figure 8).

\section{CONCLUSIONS}

OCT can be safely applied to image coronary arteries and can provide unique information to evaluate coronary stents and atherosclerotic plaques. Refinements in the technology now permit fast pullback speeds with the potential for online threedimensional reconstruction to aid in image interpretation. Although the imaging clarity is undisputed, further studies are needed to identify the clinical impact on interventional cardiology.

Contributors MAuH: First author, JL: Author of FFR and IVUS sections, VM: contribution in OCT clinical applications section, PB: Senior author, mentor and guarantor.

\section{Competing interests None.}

Provenance and peer review Not commissioned; internally peer reviewed.

Open Access This is an Open Access article distributed in accordance with the Creative Commons Attribution Non Commercial (CC BY-NC 3.0) license, which permits others to distribute, remix, adapt, build upon this work non-commercially, and license their derivative works on different terms, provided the original work is properly cited and the use is non-commercial. See: http://creativecommons.org/ licenses/by-nc/3.0/

\section{REFERENCES}

1 Falk E, Shah PK, Fuster V. Coronary plaque disruption. Circulation 1995;92:657-71.

2 Fuster V, Fayad ZA, Badimon JJ. Acute coronary syndromes: biology. Lancet 1999;353(Suppl 2):SII5-9.

3 Barlis P, Serruys PW, Gonzalo N, et al. Assessment of culprit and remote coronary narrowings using optical coherence tomography with long-term outcomes. Am J Cardiol 2008:102:391-5.

4 Arroyo LH, Lee RT. The unstable atheromatous plaque. Can J Cardiol 1998;14 (Suppl B):11B-3B.

5 Lee RT, Libby P. The unstable atheroma. Arterioscler Thromb Vasc Biol 1997:17:1859-67.

6 Davies MJ. Detecting vulnerable coronary plaques. Lancet 1996;347:1422-3.

7 Jang IK, Tearney GJ, MacNeill B, et al. In vivo characterization of coronary atherosclerotic plaque by use of optical coherence tomography. Circulation 2005; 111:1551-5.

8 Nissen SE, Yock P. Intravascular ultrasound: novel pathophysiological insights and current clinical applications. Circulation 2001;103:604-16.

9 Tuzcu EM, Bayturan O, Kapadia S. Invasive imaging: coronary intravascular ultrasound: a closer view. Heart 2010;96:1318-24.

10 Nair A, Kuban BD, Tuzcu EM, et al. Coronary plaque classification with intravascular ultrasound radiofrequency data analysis. Circulation 2002;106:2200-6.

11 Rodriguez-Granillo GA, Garcia-Garcia HM, Mc Fadden EP, et al. In vivo intravascular ultrasound-derived thin-cap fibroatheroma detection using ultrasound radiofrequency data analysis. J Am Coll Cardiol 2005;46:2038-42.

12 Jang IK, Bouma BE, Kang DH, et al. Visualization of coronary atherosclerotic plaques in patients using optical coherence tomography: comparison with intravascular ultrasound. J Am Coll Cardiol 2002:39:604-9.

13 Pijls NH, van Son JA, Kirkeeide RL, et al. Experimental basis of determining maximum coronary, myocardial, and collateral blood flow by pressure measurements for assessing functional stenosis severity before and after percutaneous transluminal coronary angioplasty. Circulation 1993;87:1354-67.

14 Tonino PA, De Bruyne B, Pijls NH, et al. Fractional flow reserve versus angiography for guiding percutaneous coronary intervention. N Engl J Med 2009;360:213-24.

15 Bech GJ, De Bruyne B, Pijls NH, et al. Fractional flow reserve to determine the appropriateness of angioplasty in moderate coronary stenosis: a randomized trial. Circulation 2001;103:2928-34.

16 Pijls NH, Klauss V, Siebert U, et al. Coronary pressure measurement after stenting predicts adverse events at follow-up: a multicenter registry. Circulation 2002;105:2950-4.

17 Diaz-Sandoval LJ, Bouma BE, Tearney GJ, et al. Optical coherence tomography as a tool for percutaneous coronary interventions. Catheter Cardiovasc Interv 2005:65:492-6.

18 Schulz C, Herrmann RA, Beilharz C, et al. Coronary stent symmetry and vascular injury determine experimental restenosis. Heart 2000;83:462-7.

19 Barlis P, Dimopoulos K, Tanigawa J, et al. Quantitative analysis of intracoronary optical coherence tomography measurements of stent strut apposition and tissue coverage. Int I Cardiol 2010;141:151-6.

20 Barlis $\mathrm{P}$, Ferrante $\mathrm{G}$, Del Furia $\mathrm{F}$, et al. In-vivo characterisation of coronary atherosclerosis with optical coherence tomography. Med J Aust 2008;188: 728.

21 Barlis P, van Soest G, Serruys PW, et al. Intracoronary optical coherence tomography and the evaluation of stents. Expert Rev Med Devices 2009;6:157-67.

22 Barlis P, Di Mario C, van Beusekom H, et al. Novelties in cardiac imaging-optical coherence tomography (OCT). Eurolntervention 2008:4(Suppl C):C22-6.

23 Barlis $\mathrm{P}$, Gonzalo N, Di Mario C, et al. A multicentre evaluation of the safety of intracoronary optical coherence tomography. Eurolntervention 2009;5:90-5.

24 Yabushita H, Bouma BE, Houser SL, et al. Characterization of human atherosclerosis by optical coherence tomography. Circulation 2002;106:1640-5.

25 Kostamaa H, Donovan J, Kasaoka S, et al. Calcified plaque cross-sectional area in human arteries: correlation between intravascular ultrasound and undecalcified histology. Am Heart J 1999;137:482-8.

26 Hao H, Gabbiani G, Camenzind E, et al. Phenotypic modulation of intima and media smooth muscle cells in fatal cases of coronary artery lesion. Arterioscler Thromb Vasc Biol 2006;26:326-32.

27 Fujimoto JG, Boppart SA, Tearney GJ, et al. High resolution in vivo intra-arterial imaging with optical coherence tomography. Heart 1999;82:128-33.

28 Tearney GJ, Jang IK, Kang DH, et al. Porcine coronary imaging in vivo by optical coherence tomography. Acta Cardiol 2000;55:233-7.

29 Kubo T, Imanishi T, Takarada S, et al. Assessment of culprit lesion morphology in acute myocardial infarction: ability of optical coherence tomography compared with intravascular ultrasound and coronary angioscopy. J Am Coll Cardiol 2007;50:933-9.

30 lakovou I, Schmidt T, Bonizzoni E, et al. Incidence, predictors, and outcome of thrombosis after successful implantation of drug-eluting stents. JAMA 2005:293:2126-30

31 Pfisterer M, Brunner-La Rocca HP, Buser PT, et al. Late clinical events after clopidogrel discontinuation may limit the benefit of drug-eluting stents: an observational study of drug-eluting versus bare-metal stents. I Am Coll Cardiol 2006:48:2584-91. 
32 van Werkum JW, Heestermans AA, Zomer AC, et al. Predictors of coronary stent thrombosis: the Dutch Stent Thrombosis Registry. J Am Coll Cardiol 2009;53:1399-409.

33 Daemen J, Wenaweser $\mathrm{P}$, Tsuchida $\mathrm{K}$, et al. Early and late coronary stent thrombosis of sirolimus-eluting and paclitaxel-eluting stents in routine clinical practice: data from a large two-institutional cohort study. Lancet 2007;369:667-78.

34 Mehran R, Lansky AJ, Witzenbichler B, et al. Bivalirudin in patients undergoing primary angioplasty for acute myocardial infarction (HORIZONS-AMI): 1-year results of a randomised controlled trial. Lancet 2009;374:1149-59.

35 Wang ZJ, Zhou YJ, Liu YY, et al. Obesity and cardiovascular thrombotic events in patients undergoing percutaneous coronary intervention with drug-eluting stents. Heart 2009;95:1587-92.

36 Joner M, Finn AV, Farb A, et al. Pathology of drug-eluting stents in humans: delayed healing and late thrombotic risk. J Am Coll Cardiol 2006;48:193-202.

37 Matsumoto D, Shite J, Shinke T, et al. Neointimal coverage of sirolimus-eluting stents at 6-month follow-up: evaluated by optical coherence tomography. Eur Heart J 2007;28:961-7.

38 Barlis P, Regar E, Serruys PW, et al. An optical coherence tomography study of a biodegradable vs. durable polymer-coated limus-eluting stent: a LEADERS trial sub-study. Eur Heart J 2010;31:165-76.

39 Guagliumi G, Sirbu V, Musumeci G, et al. Strut coverage and vessel wall response to a new-generation paclitaxel-eluting stent with an ultrathin biodegradable abluminal polymer: Optical Coherence Tomography Drug-Eluting Stent Investigation (OCTDESI). Circ Cardiovasc Interv 2010;3:367-75.
40 Takano M, Yamamoto M, Inami S, et al. Long-term follow-up evaluation after sirolimus-eluting stent implantation by optical coherence tomography: do uncovered struts persist? J Am Coll Cardiol 2008:51:968-9.

41 Gonzalo N, Barlis P, Serruys PW, et al. Incomplete stent apposition and delayed tissue coverage are more frequent in drug-eluting stents implanted during primary percutaneous coronary intervention for ST-segment elevation myocardial infarction than in drug-eluting stents implanted for stable/unstable angina: insights from optical coherence tomography. JACC Cardiovasc Interv 2009;2:445-52.

42 Barlis $\mathrm{P}$, Regar E, Serruys PW, et al. An optical coherence tomography study of a biodegradable vs. durable polymer-coated limus-eluting stent: a LEADERS trial sub-study. Eur Heart J 2010;31:165-76.

43 Barlis P, Sianos G, Ferrante G, et al. The use of intra-coronary optical coherence tomography for the assessment of sirolimus-eluting stent fracture. Int I Cardiol 2009:136: $16-20$

44 Schinkel AF, Barlis P, van Beusekom HM, et al. Images in intervention. Optical coherence tomography findings in very late (4 years) paclitaxel-eluting stent thrombosis. JACC Cardiovasc Interv 2008;1:449-51.

45 Ormiston JA, Serruys PW, Regar E, et al. A bioabsorbable everolimus-eluting coronary stent system for patients with single de-novo coronary artery lesions (ABSORB): a prospective open-label trial. Lancet 2008;371:899-907.

46 Serruys PW, Ormiston JA, Onuma Y, et al. A bioabsorbable everolimus-eluting coronary stent system (ABSORB): 2-year outcomes and results from multiple imaging methods. Lancet 2009;373:897-910. 